\title{
Designing Hydel Power Generation Capacity using a Mini/Micro Hydro Power Plant at Left Bank Outfall Drain Drainage System, near Goth Ahori, Jhuddo, Sindh
}

\author{
Amjad Ali ${ }^{1}$, Fahad Saleem Baig ${ }^{2 a}$, Abdul Hameed Memon ${ }^{2 b}$
}

RECEIVED ON 28.11.2018, ACCEPTED ON 26.07.2019

\begin{abstract}
Energy is considered as a vital sign of any country. The energy resource of any country is governed by their owned resources either through fossiliferous or alternative/renewable energy reserves. Due to depleting reserves of fossil fuel, countries including Pakistan are now focusing and converting themselves on renewable energy sources. Out of the different renewable sources, Hydel Power is among those indigenous sources which are considered as cheap, efficient and environmentally friendly. Pakistan is among those countries, which have the largest irrigation system which portrays a huge hydel potential within it. Government of Pakistan has also identified different potential sites where Hydel Energy can be obtained. However, apart from the recognized potential sites, there are still many streams/canals/ drains that can also be studied for their hydro potential and estimated generation capacity using mini/micro hydropower plant. Different studies have been carried out in calculating the energy potential of canals. In this paper, Hydropower Potential (HPP) of a Drainage System that is Left Bank Outfall Drain (LBOD), at Sindh has been calculated using field-based data parameters such as hydraulic depth, the width of the canal and flow velocity. Other studies were also reviewed for data collection. Based on the calculated HPP, five types of turbines with their benefits have been identified and proposed. This study concludes that different locations of LBOD can be considered for setting up a micro hydropower plant; however, a vertical head through extended penstock or weir needs to be considered for an effective hydropotential.
\end{abstract}

Keywords: Hydel Power, Power Generation, and Energy Crises.

\section{INTRODUCTION}

$\mathrm{E}$ nergy is one of the key driving force and a necessity which contributes to stabilizing and powering the economy and social stability of any country [1]. This driving force requires the supply of energy mix to be balanced with incurring energy demand. A shortfall of energy supply highly contributes to decreasing per capita energy consumption which in turns shifts into social unrest and un-stability of the whole nation. Unfortunately,
Pakistan is among those countries which are trying to cope up with the continuous energy demand. Fig. 1 depicts the year wise generation capacity along with the demand.

The Fig.1 shows that the demand - capacity gap remained stagnant to approx. 4000MW from the year 2013 till 2017; however, with the incoming new generation projects, it is expected that this gap will decrease up to 2000MW.

${ }^{1}$ Centre of Research Excellence in Renewable Energy (CoRE-RE), King Fahad University of Petroleum and Minerals, Dhahran, Saudi Arabia. Email: amjad.ali@kfupm.edu.sa (Corresponding Author)

${ }^{2}$ Faculty of Engineering Sciences and Technology, Graduate School of Engineering Sciences and Information Technology, Hamdard University, Karachi, Pakistan. Email: ${ }^{\mathrm{S} f \mathrm{fs}} 1981 @$ gmail.com, bhameed.memon@ @amdard.edu.pk

This is an open access article published by Mehran University of Engineering and Technology, Jamshoro under CC BY 4.0 International License. 


\section{Designing Hydel Power Generation Capacity using a Mini/Micro Hydro Power Plant at Left Bank Outfall}

Drain Drainage System, near Goth Ahori, Jhuddo, Sindh

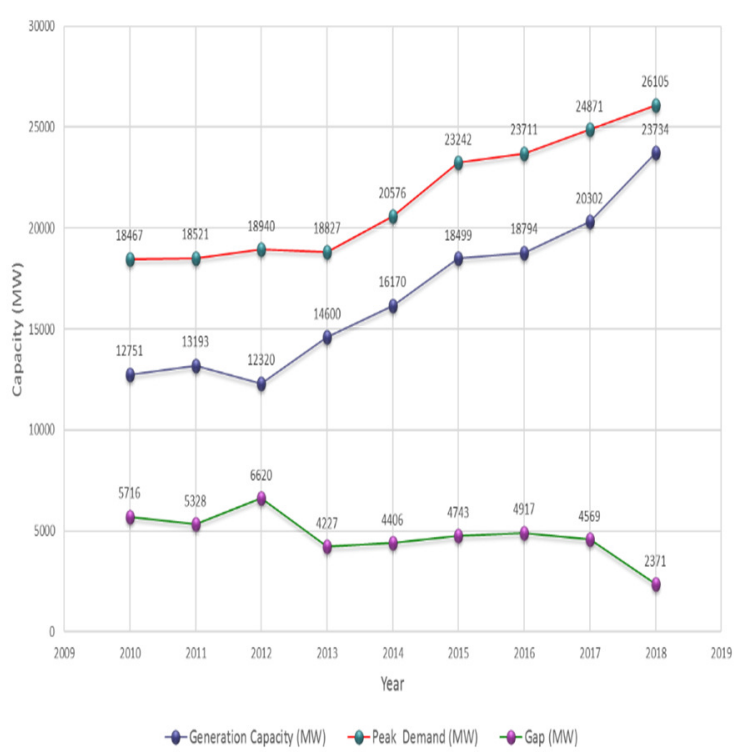

FIG. 1. PAKISTAN ENERGY DEMAND SUPPLY STATISTICS (CALCULATED FROM HDIP PROVIDED CAPACITY PROJECTION WITH ENERGY DEMAND PROJECTION)

To overcome the above-mentioned energy gap and reduction in dependency of imported fuel, Government of Pakistan (GOP) has recognized different areas in which there exist enormous energy potential via indigenous energy. This includes exploration for natural gas and crude oil, exploitation of indigenous coal, solar energy, wind energy, nuclear energy, hydel energy, and biogas, etc.

From the above list of energies, Hydel Energy is one of the preferred renewable energy potentials. The reason behind this is that our planet Earth is covered by at least $71 \%$ of water surface. It is also one of the cheapest energy sources with negligible carbon emission [2].

This paper focuses on calculating HPP of one of a Drain System i.e. LBOD near Goth Ahori, Jhuddo, Sindh using Mini/Micro HPP taking into account, site measured data i.e. head and water flow rate, selection of hydraulic turbine and an estimated electrical power generation.

The micro HPP system, if implemented, can provide decentralized electricity to Goth Ahori and other nearby villages without using the online grid system [3].
Different studies and researches have been carried out on different aspects of the micro hydropower including its potential, economic feasibility, and design in different countries.

Usama et. al. [4] focused on the usage of twisted blade turbine system to generate electricity from a stream line water flow. They installed a prototype turbine with an adjustable twisted blade on different locations of Lahore Canal in Pakistan. The study showed that energy output can be increased by changing the blade angles. Further, the available energy of the canal depended on the amount of water passing from the turbine and the square of the velocity of the water.

Akhter et. al. [5] provided an idea of a Super Grid Model, which if installed, would suffice the transmission from power generation (either from thermal or renewable sources) to load centers in Pakistan. Although the concept behind our paper is generating power on those potential areas where online grid system is not available; however, if the micro-hydro power plants are connected with these super grid models, power can be supplied to a wider region then an off-grid system.

Pasalli et. al. [17] studied the hydropower potential of Hink River, Indonesia, in case a micro-hydro power plant is planned. With a design of Cross Flow Type Turbine, if installed can be transferred to 5 villages around Hink District with a payback period of 17.32 years.

Razan et. al. [6] reviewed the different locations of Bangladesh where there exists a micro hydropower potential and suggested that the northeastern hilly regions of Bangladesh, due to high stream flow rate has better hydro-electric potential. Further, as Bangladesh is home to 232 rivers, so there exist a great micro-hydro potential with a run of river type turbine system.

Elbatran et. al. [20] discussed about the technical and economic performance of micro HPP. Two types of turbine i.e. Impulse and Reaction Turbines were discussed for performance which can be selected based on water flow and head. 


\section{HYDEL ENERGY SCENARIO IN PAKISTAN}

Pakistan is one of those countries which is blessed with the largest contiguous irrigation system in the world. This system is known as the Indus Basin Irrigation System (IBIS) and is irrigating approximately 18 million Hectares of land [4]. This IBIS system comprises of 43 principal canals in which 23 canals are in Punjab, 15 are in Sindh and 5 are in Khyber Pakhtunkhwa (KPK). Seventeen of these canals have a head capacity of $198-425 \mathrm{~m}^{3} / \mathrm{s}$. Further, there are 8 major link canals with a head capacity ranging from $184-614.5 \mathrm{~m}^{3} / \mathrm{s}$ [5].

This major irrigation system along with the drainage system has a prodigious potential in terms of creating eco-friendly hydropower in smaller, medium to a larger scale. It is estimated that about 60,000 MW of hydropower resources are available in Pakistan, in which,

- 142 potential sites with an estimated capacity of 24,736 MW have been identified in KPK,

- 296 potential sites with an estimated capacity of 7,291 MW identified in Punjab,

- A number of potential sites with an estimated capacity of 6,450 MW identified in Azad Jammu \& Kashmir (AJ\&K).

- Numerous promising sites with an estimated capacity of about 11,876 MW in Gilgit-Baltistan

- 18 potential sites with an estimated capacity of 193MW have been identified in Sindh

Fig. 2 provides a graphical illustration of the province wise distribution of hydropower resources.

Whereas until 2010 the total installed capacity from the hydropower projects was $6,720 \mathrm{MW}$, out of which, 3,849 MW was in KPK, 1,699 MW was in Punjab, 1,039 MW in AJ\&K and 133MW in Gilgit - Baltistan.

Hydropower Potential identified by the GOP in Sindh are on Nai Gaj Fall on Nai River, Kotri and Guddu barrages and Rohri and Nara canals. Feasibility studies of the Rohri Canal and Guddu Barrage Projects have also been completed [6]. Fig. 3 illustrates the proposed locations of Sindh where potential hydropower can be installed as identified by GOP.

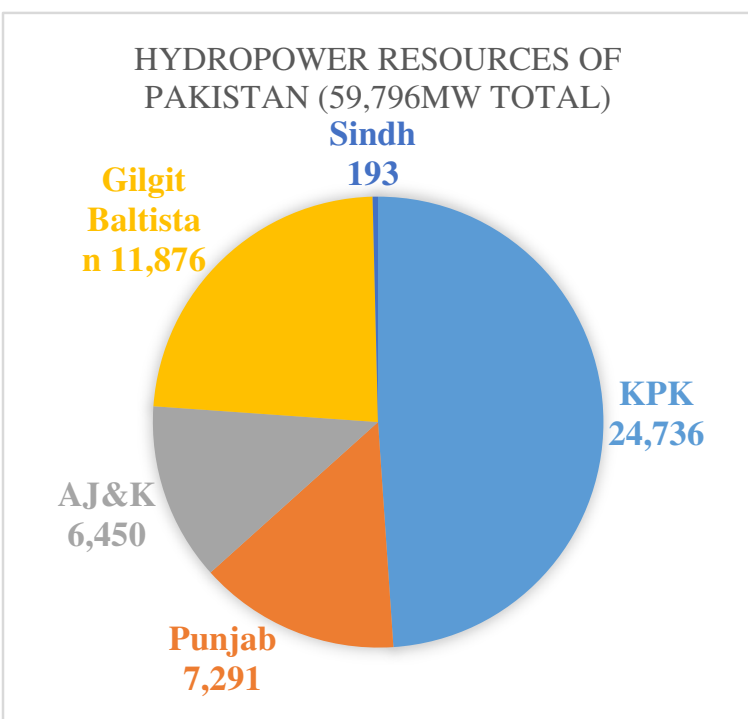

FIG.2. PROVINCE WISE POTENTIAL HYDROPOWER RESOURCES (CALCULATED FROM HYDROPOWER POTENTIAL OF PAKISTAN IDENTIFIED BY GOP) [6]

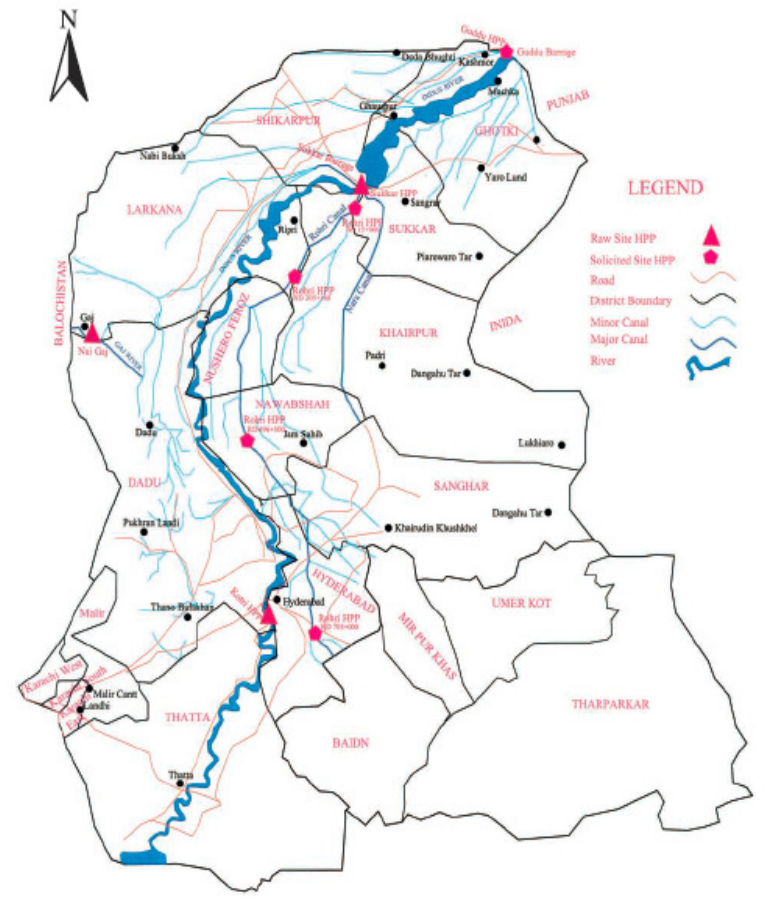

FIG. 3. IDENTIFIED HYDROPOWER POTENTIAL (RAW \& SOLICITED) SITES [6]

Although, these are major sites in which GOP has identified the HPP; however, apart from the aboveidentified canals; there can be a lot more HP potential in the 15 major canals; if a dam-less or more 
specifically run of river type mini / micro hydropower plants are planned.

In addition to these canal system, GOP initiated different projects in Sindh to eradicate and control the waterlogging and salinity problems in the irrigated areas; including Salinity Control and Reclamation Projects (SCARPs), Chashma Command Area Development, LBOD, Sukh-Beas Drainage Scheme, etc. The ISS (Indus Special Study) was conducted for the construction of two major surface drainage projects, the Sukh-Beas Drainage Scheme and the LBOD. Water and Power Development Authority (WAPDA) prepared a Project Planning Report for these projects in 1969 [5].

\section{MATERIALS AND METHOD}

\subsection{Site Selection and Description}

For this study, LBOD was selected as a Hydropower Potential Drain by which hydel energy can be provided and supplied to the outskirts and downtrodden areas of the Sindh Region. $1^{\text {st }}$ phase of LBOD spinal drain with a surface drain of $968 \mathrm{~km}$ was initiated in 1973 and was commissioned in 1986 by GOP. The remaining LBOD component project consisted of 75 saline water tube wells, $1,814 \mathrm{~km}$ long surface drains and 2,817 km of Tile + Interceptor Drains. The commutation physical progress until 1998 was $94 \%$. Details of LBOD Stage-I is tabulated in Table 1 [5].

\begin{tabular}{|c|c|c|c|c|}
\hline \multicolumn{5}{|c|}{ TABLE 1: LBOD STAGE - I DRAINAGE PROJECT } \\
DETAILS \\
\hline SCARPS & $\begin{array}{c}\text { Gross } \\
\text { Area } \\
(\mathrm{M} . \mathrm{Ha} .)\end{array}$ & $\begin{array}{c}\text { Tube } \\
\text { Wells } \\
(\mathrm{No})\end{array}$ & $\begin{array}{c}\text { Surface } \\
\text { Drains } \\
(\mathrm{km})\end{array}$ & $\begin{array}{c}\text { Tile } \\
\text { Drains } \\
(\mathrm{ha})\end{array}$ \\
\hline $\begin{array}{c}\text { LBOD } \\
\text { Stage-I }\end{array}$ & 0.577 & 2,175 & 1,814 & 22,260 \\
\hline \multicolumn{5}{|c|}{ Source: Monthly Progress Report Water Wing } \\
(May 1999) [5]
\end{tabular}

The LBOD passes through Nawabshah, Sanghar and Mirpurkhas Districts and lies between $24^{\circ} 10^{\prime}$ and $26^{\circ}$ $40^{\prime} \mathrm{N}$, and, 68 $09^{\prime}$ and $69^{\circ} 26^{\prime} \mathrm{E}$ [7].

\subsection{Field Survey and Data Collection}

A 2-day field survey was carried out in which, an LBOD Canal Drop near Goth Ahori, Jhuddo, Sindh having geographical coordinates with the latitude of $25^{\circ} 00.067^{\prime} \mathrm{N}$ and longitude of $069^{\circ} 24.208^{\prime} \mathrm{E}$ was selected. Fig. 4 illustrates the actual photographic location of the selected site, while data collected during a site visit is tabulated in Table 2.

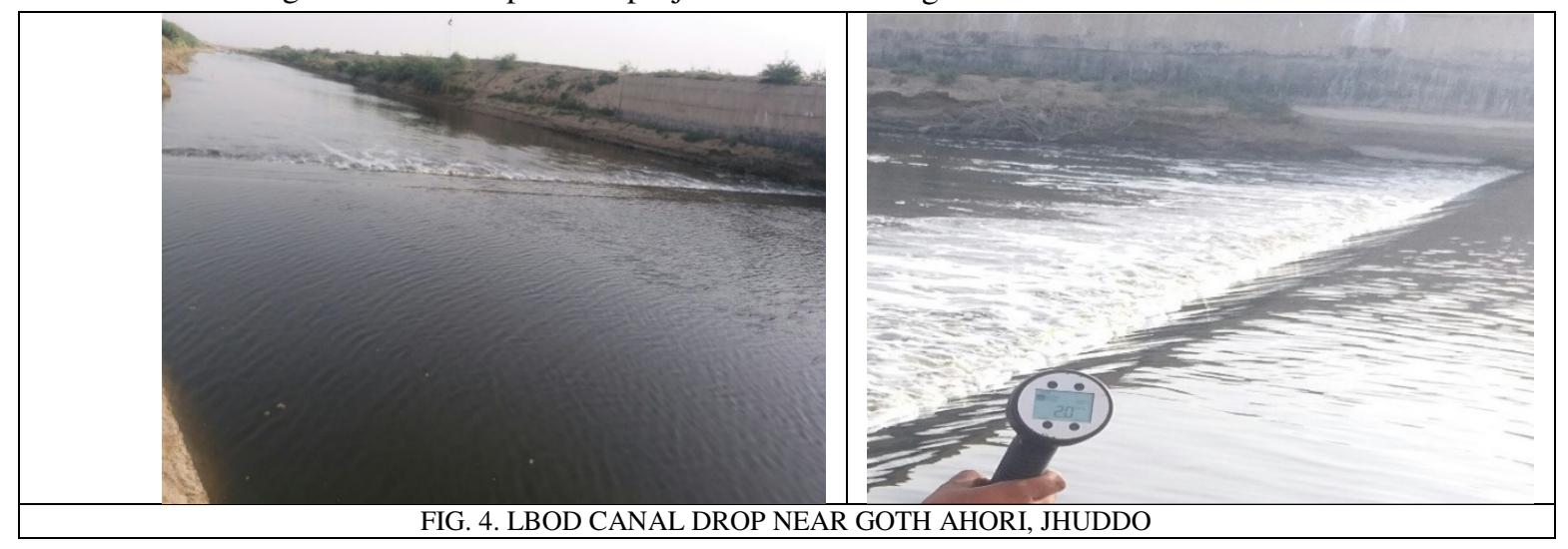

\begin{tabular}{|c|c|c|c|c|c|c|}
\hline \multicolumn{6}{|c|}{ TABLE. 2. DATA COLLECTED FOR HYDROPOWER POTENTIAL AT SITE FOR THIS STUDY: } \\
\hline \multirow{2}{*}{ Date } & Time & $\begin{array}{c}\text { Hydraulic } \\
\text { Depth at Left } \\
\text { Bank }(\mathrm{m})\end{array}$ & $\begin{array}{c}\text { Top Width } \\
(\mathrm{m})\end{array}$ & $\begin{array}{c}\text { Cross } \\
\text { Sectional Area } \\
\left(\mathrm{m}^{2}\right)\end{array}$ & $\begin{array}{c}\text { Flow Velocity } \\
(\mathrm{m} / \mathrm{s})\end{array}$ & $\begin{array}{c}\text { Volumetric } \\
\text { Flow }\left(\mathrm{m}^{3} / \mathrm{s}\right)\end{array}$ \\
\hline \multirow{2}{*}{12.04 .2018} & 1600 & 0.15 & 28.96 & 4.40 & 1.04 & 4.56 \\
\cline { 2 - 8 } & 1800 & 0.10 & 28.96 & 2.94 & 0.61 & 1.79 \\
\hline 13.04 .2018 & 1000 & 0.13 & 28.96 & 3.68 & 0.79 & 2.91 \\
\hline \multicolumn{2}{|c|}{ Average 2018} & 0.13 & 28.96 & 3.67 & 0.81 & 3.09 \\
\hline
\end{tabular}


Another field survey was carried out in 2016; in which average depth was found to be $2 \mathrm{~m}$, top width was $28.96 \mathrm{~m}^{2}$, while, the average velocity was $0.554 \mathrm{~m} / \mathrm{s}$. The resultant volumetric flow was calculated as $32.087 \mathrm{~m}^{3} / \mathrm{s}$.

The flow velocity was measured using FP-111 Global Water® Flow Probe, depth was measured using plum bob dipping tape; and, the width of the canal was measured using a measuring tape. The data collected is given in Table 2.

Sindh Irrigation and Drainage Authority also carried out a hydrological and hydraulic simulation study of LBOD in 2012 [8]. Based on the study, for actual geometry of LBOD at RD575, the channel had a hydraulic depth of $3.07 \mathrm{~m}$, the average velocity was $0.792 \mathrm{~m} / \mathrm{s}$, and top width of $49.231 \mathrm{~m}$. The resultant volumetric flow was $119.7 \mathrm{~m}^{3} / \mathrm{s}$ (All values of this study has been converted to SI System). Fig. 5 shows a cross-section of LBOD RD 575.

\section{RESULTS AND DISCUSSION}

\subsection{Design Parameters}

For the installation of an HPP, different parameters are required to be taken into consideration [9]. They include:

\subsection{Flow Duration Curve [9]}

The flow of water at a cross-section of any river varies over time due to differential precipitation rates. Water discharge or flow can be measured during the day through different devices. The mean daily flow rate can thus be obtained by averaging measurements taken throughout the same day. Annual historical mean daily flow values are obtained by the mean annual water flow value for a given year.

Planning for a HPP requires an exhaustive data of the flow regime. There are 2 techniques for annual flow values which are (1) annual hydrograph and the (2) Flow Duration Curve (FDC). The annual hydrograph is simpler in the sense that it provides daily flow variations during a calendar year. However, the FDC is more suitable for energy calculation for hydropower. The FDC illustrates temporal flow distribution of a preceding year/s. All flow values are organized from highest to lowest values. The frequencies are converted into $\%$ of the total number of days which form the basis for the FDC [10].

For this research paper, FDC has not been produced due to time constraints; however, 3 readings of the flow were measured during the whole day. In addition, flow values were also obtained from different other sources.

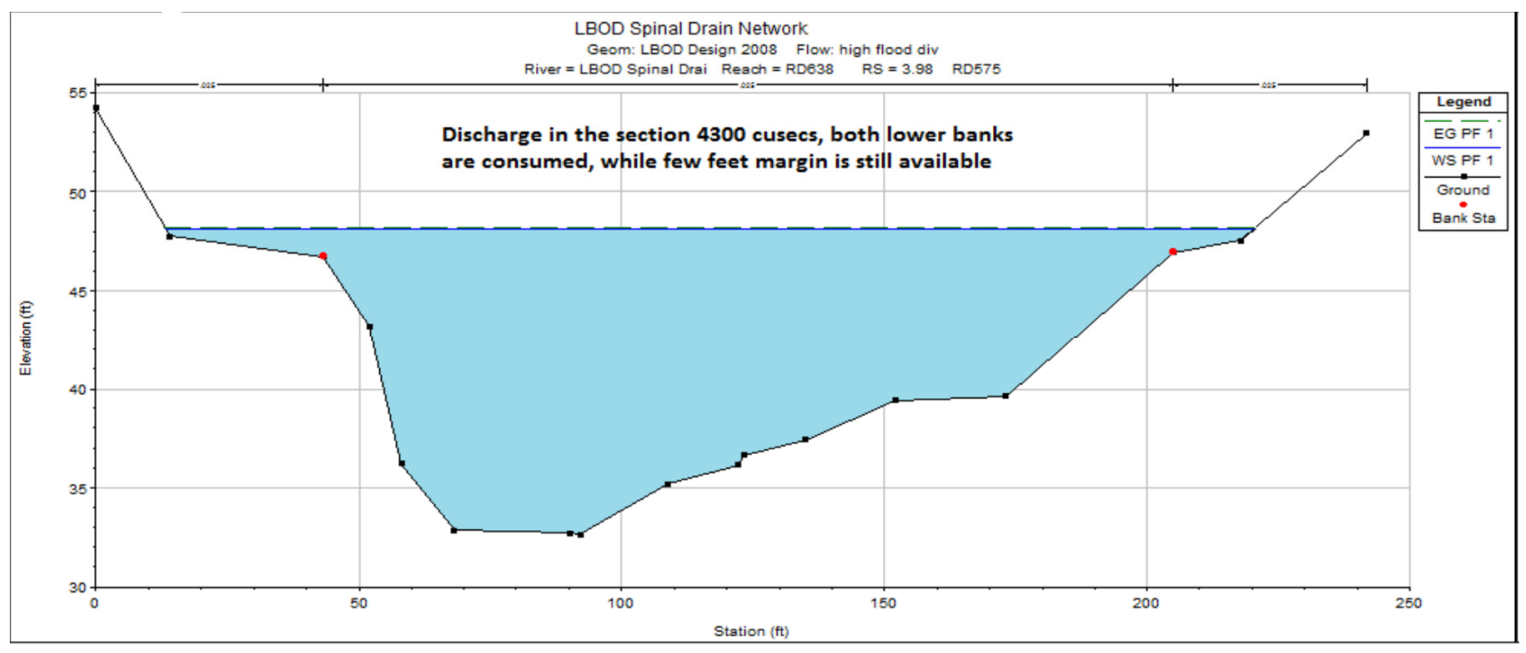

FIG. 5. CROSS SECTION OF RD-575 OF LBOD (SIDA STUDY 2012) [8] 


\subsection{Flow Rate Measurements [11]}

The flow rate was calculated using the velocity-area method for this study.

Area of the drain was calculated assuming the drain to be a complete rectangle as:

Area (A) = Top Width (W) x Hydraulic Depth (D)

Velocity (V) was measured using flow probe; however, it can also be calculated using floating object technique, in which time elapsed to move a floating object from one point to another with a pre-measured length is measured. This length is divided by the calculated time to obtain velocity of the given section.

Lastly, the flow rate $(\mathrm{Q})$ was calculated by:

Flow Rate $(\mathrm{Q})=\mathrm{A}$ x V

Using the data collected and the above-mentioned flow calculations, volumetric flow rate has been established and tabulated in Table 3.

\begin{tabular}{|c|c|c|}
\hline \multicolumn{3}{|c|}{ TABLE 3: CALCULATED FLOW RATES FROM THE } \\
THREE STUDIES
\end{tabular}

\subsection{Weir for a Low Discharge Rivers [11]}

Q was found very low i.e. $3.09 \mathrm{~m}^{3} / \mathrm{s}$ during the field survey 2018; therefore, to increase the flow rate, a weir of either rectangular or $\mathrm{V}$ notch shape can be installed. However, the elevation of the weir should be such that it does not affect the stability of the channel. Fig. 6 illustrates a rough representation of a run of river type mini / micro hydropower plant and its major components.

\subsection{Vertical Head [10]}

To generate hydropower, difference in 2 water surface elevations is required. This difference is called as Head or Vertical Head. This elevation difference creates gravitational potential energy which is converted to hydropower by using suitable turbines.

Based on the head, HPP is segregated into the following types:

High Vertical Head where $\mathrm{H}>100 \mathrm{~m}$

Medium Vertical Head where $\mathrm{H}$ is from 30 to $100 \mathrm{~m}$

Low Vertical Head where $\mathrm{H}<30 \mathrm{~m}$

The vertical gross head was found to be $0.61 \mathrm{~m}$ at the Canal Drop near Goth Ahori, Jhuddo shown in Fig. 4; which shows the head to be classified as Low Vertical Head; hence, suitable for a run of river type micro/pico hydropower.

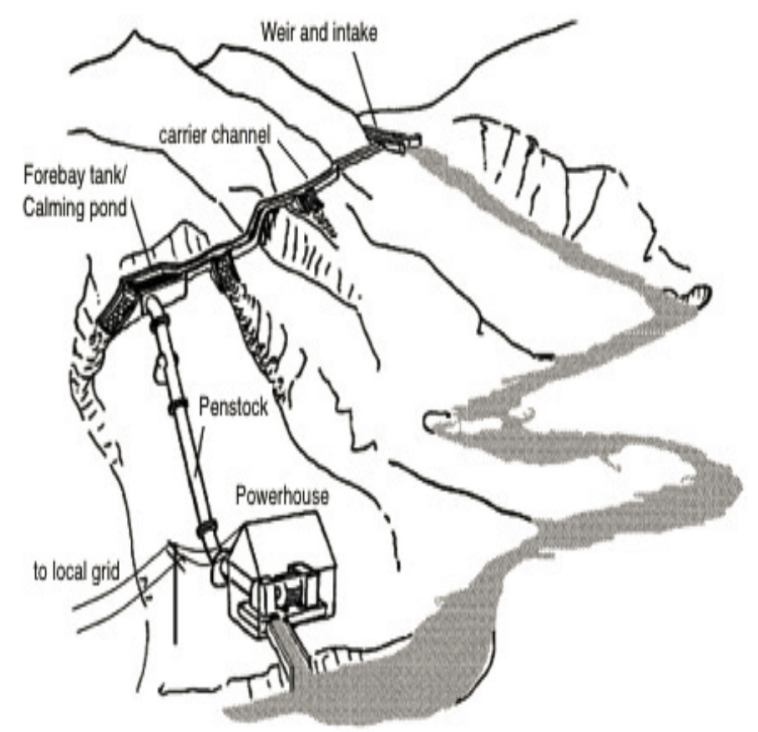

FIG. 6: LAYOUT OF A MINI HYDRO POWER PLANT SITE LAYOUT (ADAPTED FROM [12])

\subsection{Turbine Power [13]}

Flowing and falling water stores a certain amount of kinetic energy with it. Hydropower converts this flowing water energy into mechanical energy, using a water wheel or turbine. This energy can then be converted into electricity through means of an electric generator. [14]

A hydel power or a Turbine Power is directly proportional to the product of head and flow rate. [10] This gives the general formula of the turbine power as: 


$$
\mathrm{P}_{\mathrm{t}}=\frac{\rho \times \eta \times \mathrm{g} \times \mathrm{Q} \times \mathrm{H}}{10^{6}}
$$

where $\mathrm{P}_{\mathrm{t}}$ is Turbine Gross Power in MW, $\eta$ is overall efficiency of power plant normally considered as $87 \%$, $\rho$ is density of water, in which although the water may have high density, however, for the ideal condition it is used as $1000 \mathrm{~kg} / \mathrm{m}^{3} . \mathrm{g}$ is gravitational acceleration which is $9.8 \mathrm{~m} / \mathrm{s}^{2}$, $\mathrm{Q}$ is the volumetric flow rate calculated above for 3 cases in $\mathrm{m}^{3} / \mathrm{sec}, \mathrm{H}$ is Vertical Head which was calculated as $0.61 \mathrm{~m}$

Using the data collected for the site and the above power formula, $\mathrm{P}_{\mathrm{t}}$ is calculated and tabulated for the 3 cases as shown in Table 4:

\begin{tabular}{|c|c|c|c|}
\hline \multicolumn{4}{|c|}{ TABLE 4: TURBINE GROSS POWER CALCULATED FOR } \\
THE THREE STUDIES
\end{tabular}

This shows that with a minimum flow of $3.09 \mathrm{~m}^{3} / \mathrm{s}$; $16 \mathrm{KW}$ can be produced, while, with an average flow rate of $32.1 \mathrm{~m}^{3} / \mathrm{s}, 167 \mathrm{KW}$ can be produced; and with maximum flow, up to $600 \mathrm{KW}$ can be produced.
By using the Turbine Power $\mathrm{P}_{\mathrm{t}}$, Flow Rate $\mathrm{Q}$ and Vertical Head $\mathrm{H}$; Turbine Dimensions including turbine height, area, and turbine type can be calculated. Williamson et. al. [15] devised qualitative and semi-quantitative selection criteria for turbines. As per Figs. 7-8, a minimum of the $1 \mathrm{~m}$ vertical head is required. In case, the vertical head is increased within a range of 1-3 $\mathrm{m}$ and with an average flow rate of $32 \mathrm{~m}^{3} / \mathrm{sec}, 4$ types of turbines can be studied further for the Site i.e. Archimedes Screw Turbine, Impulse Turbine as Cross Flow or Reaction Turbine as Kaplan and Francis (for 10m Head).

In addition, the site can also be studied for a Gravitational Vortex Hydropower Plant (GVHP). Table 5 provides a proposed turbine type considering the flow rates, site selection, vertical head. Table 5 is to be considered as only for informative and further investigation of the design parameters.

\subsection{Archimedes Screw Turbine}

This kind of simple turbine is becoming more attractive for lower head sites as low as $1 \mathrm{~m}$, and large flow rates [19]. Raza et. al. [20] projected a low head Archimedes screw turbine, in which the screw efficiency was found to be dependent on the flow rate and the inclination angle. Further, the water capacity was found increased while efficiency was found decreased with few inclined angles and vice versa. Maximum model efficiency was found to be $86 \%$. This is a run of river type turbine.

\subsection{Turbine Selection [16-17]}

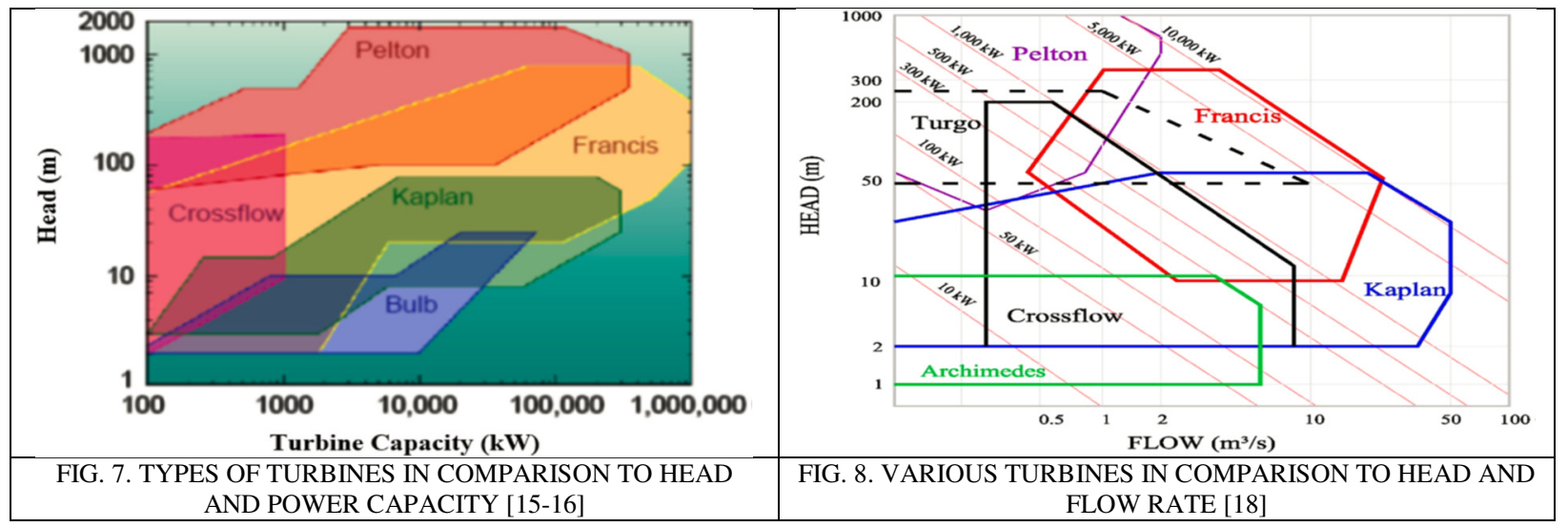

Mehran University Research Journal of Engineering and Technology, Vol. 39, No. 3, July 2020 [p-ISSN: 0254-7821, e-ISSN: 2413-7219] 


\begin{tabular}{|c|c|c|c|c|}
\hline \multicolumn{5}{|c|}{ TABLE 5. PROPOSED TURBINE TYPES FOR THE THREE STUDIES } \\
\hline $\begin{array}{l}\text { Data Interval for } \\
\text { LBOD }\end{array}$ & $\begin{array}{l}\text { Flow } \\
\text { Rate } \\
(\mathrm{Q}) \\
\mathrm{m}^{3} / \mathrm{s} \\
\end{array}$ & $\begin{array}{l}\text { Vertical } \\
\text { Head } \\
(\mathrm{H}) \text { in } \mathrm{m}\end{array}$ & Proposed Turbine Types & Remarks \\
\hline $\begin{array}{l}\text { Field Survey } 2018 \text { at } \\
\text { Goth Hori - Jhuddo }\end{array}$ & 3.09 & \multirow{3}{*}{0.61} & $\begin{array}{l}\text { - Archimedes, } \\
\text { Crossflow, and } \\
\text { Kaplan as Run of } \\
\text { River Type } \\
\text { - Gravitational Vortex } \\
\text { as Run of River Type }\end{array}$ & \multirow{3}{*}{$\begin{array}{l}\text { Vertical Head is very } \\
\text { small therefore to } \\
\text { increase the Head to } \\
1-3 \mathrm{~m} \text {; a V- notch or } \\
\text { rectangular weir with } \\
\text { penstock would be } \\
\text { required }\end{array}$} \\
\hline $\begin{array}{c}\text { Field Survey } 2016 \\
\text { near Goth Ahori - } \\
\text { Jhuddo }\end{array}$ & 32.087 & & $\begin{array}{l}\text { - Kaplan as Run of } \\
\text { River Type } \\
\text { - Gravitational Vortex } \\
\text { as Run of River Type }\end{array}$ & \\
\hline $\begin{array}{c}\text { SIDA Survey } 2012 \text { at } \\
\text { RD575 }\end{array}$ & 119.7 & & $\begin{array}{c}\text { - Kaplan and Francis as } \\
\text { Run of River Type }\end{array}$ & \\
\hline
\end{tabular}

\subsection{Archimedes Screw Turbine}

This kind of simple turbine is becoming more attractive for lower head sites as low as $1 \mathrm{~m}$, and large flow rates [19]. Raza et. al. [20] projected a low head Archimedes screw turbine, in which the screw efficiency was found to be dependent on the flow rate and the inclination angle. Further, the water capacity was found increased while efficiency was found decreased with few inclined angles and vice versa. Maximum model efficiency was found to be $86 \%$. This is a run of river type turbine.

\subsection{Impulse Turbine [10]}

The major benefits of impulse turbines are:

- Easily adapted to differential discharges with an approx. persistent efficiency

- Penstock overpressure can be avoided; so, runner over-speeding can easily be controlled

- Maintenance is quite easy

- These turbines work better with high vertical heads

In the Crossflow impulse turbine, water flows transversely through the turbine, entering from the edge and exiting on the opposite side thereby revolving the turbine. This kind of turbine can be applied in both horizontal and vertical arrangements. This type of turbine can be used at a higher flow rate and lower head than the Pelton and Turgo turbines.
The operational efficiency depends on geometrical parameters i.e. a number of blades, runner diameter, nozzle entry, arc and angle of attack.

\subsection{Reaction Turbines [10]}

Reaction turbines use flow rate to produce hydrodynamic lift that propels the runner blades. Major benefits of reaction turbines are:

- Less installation space (runners are reduced as compared to Pelton runners)

- High net vertical head with better protection against downstream high flood levels as it can function easily submerged

- High runner speed

- Higher efficiencies for higher power values

Kaplan reaction turbine is a propeller turbine with adjustable runner blades. The adjusting turbine blades and guide vanes increase the overall costs; however, efficiencies are increased over a wide range of flows. Due to adjustment in blades, Kaplan is a suitable option as run-of-river type turbine

Francis reaction turbine, on the other hand, is the most common water turbine in use. Water flows radially into the runner and exits axially into the draft tube. The runner is enclosed by a spiral case in which guide vanes are integrated to direct the water tangentially to the runner 


\subsection{Gravitational Vortex Hydropower [21]}

This kind of hydropower exploits the energy of vortex flow. A vortex is created in a cylindrical basin with a tangential inlet from a penstock or open drain and a central conical outlet just inside the basin. A vertical turbine is placed in the middle of the vortex with the highest rotational speed. This run of river type turbine propels with the whirling flow generating mechanical energy and in turns electrical energy by using a generator.

\section{CONCLUSION}

This study concludes that LBOD can also be considered as a hydropower potential site in which a micro hydropower plant can easily be installed and operated. The major issue is the vertical head, for which either an extended penstock is required, or, a weir can be installed to increase the overall vertical head. Further, a qualitative assessment for turbine selection has been adopted in which 04 types of turbines were selected for the Hydropower. However, this requires a detailed study in which FDC for LBOD needs to be generated for a minimum of the 5-year period, topography for maximum vertical head also needs to be found.

\section{ACKNOWLEDGMENTS}

This study acknowledges the support and collaboration of Faculty of Engineering, Sciences \& Technology, Hamdard University, Karachi, Pakistan.

\section{REFERENCES}

[1] Khalil, M. S., Khan, N. A., and Mirza, I. A., "Renewable energy in Pakistan: status and trends", Alternate Energy Development Board Publication, Ministry of Water \& Power, 2014, http://www.mowp.gov.pk/mowp/userfiles1/file/u ploads/publications/repk.pdf.

[2] Rahman, M. M., Hong, T. J., and Tamiri, "F. M. Effects of Inlet Flow Rate and Penstock's Geometry on the Performance of Gravitational Water Vortex Power Plant", $20188^{\text {th }}$ International Conference on Industrial Engineering and Operations Management- IEOM Society, ISBN:
978-1-5323-5944-6, No. ID 688, pp. 2968, Bandung, Indonesia, March 6-8, 2018.

[3] Marian, G. M., Sajin, T., Florescu, I., Nedelcu, D.I., Osthie, C.N., and Birsan, C., "The Concept and Theoretical Study of Micro Hydropower plant with Gravitational Vortex and Turbine with Rapidity Steps", Buletinul - The General Association of the Engineers in Romania (AGIR), Vol 3/2012, No. 1387, pp. 219-226, 2012.

[4] Usama, M., Habib, S., and Hussain, H., "Power generation from canal system using adjustable Twisted Blade Turbine," 2015 International Conference on Emerging Technologies (ICET), pp. 1-4, Peshawar, Dec 19 -20 2015.

[5] Akhter, F., Memon, A. A., and Shaikh, N. N., "A Proposed Supergrid Model for National Transmission Network of Pakistan", Mehran University Research Journal of Engineering and Technology, [S.1.], v. 36, n. 1, pp. 149-158, Jan. 2017.

[6] Razan, J. I., Islam, R. S., Hasan, R., Hasan, S., \& Islam, F., "A Comprehensive Study of MicroHydropower Plant and Its Potential in Bangladesh," ISRN Renewable Energy, vol. 2012, Article ID 635396, 10 pages, 2012.

[7] Tvedt, T., Jakobsson, E., Coopey, R., and Oestigaard, T., "A History of Water Vol 1: Water Control and River Biographies", IB Tauris, Part 1-2, pp 35, London, 2006.

[8] Framji, K.K., Garg, B.C., and Luthra, S.D.L., "Irrigation \& Drainage in the World - A Global Review - Pakistan Chapter", International Commission of Irrigation and Drainage, Vol II, pp xvii, Delhi, 1982

[9] "Hydro power resources of Pakistan". Annual Report of Private Power and Infrastructure Board, Government of Pakistan, Ch 6, Islamabad, February 2011

[10] Kori, S.M., Memon, N. A., and Lasharia, B. K., "Analysis of Seepage from Elevated Saline Disposal Channels of LBOD-1 Nawabshah Component", 2016 International Conference on Energy, Environment and Sustainable Development (EESD), VII-7, No. ID EESD_2016_210, MUET Jamshoro, Nov 1-3 2016.

[11]"Hydrology and Hydraulic Simulation for Preparation of Regional Plan for the Left Bank 
Indus, Delta and Coastal Zone", Final ReportPhase II of The Louis Berger Group Inc., Volume -III, Sindh Irrigation and Drainage Authority, May 2012

[12] Nasir, B. A., "Design considerations of microhydro-electric power plant", Energy Procedia, Vol 50, pp. 19-29, 2014,

[13]"A Guide for Developers and Investors." International Finance Corporation. World Bank Group, Germany, 2015

[14] Penche, C., "Layman's Guidebook on how to Develop a Small Hydro Site", European Small Hydropower Association (ESHA), $2^{\text {nd }}$ Ed., DG XVII, European Commission, Belgium, June, 1998.

[15]Hanafi, J., and Riman, A., "Life Cycle Assessment of a Mini Hydro Power Plant in Indonesia: A Case Study in Karai River", Procedia CIRP, Vol 29, pp 444-449, 2015.

[16] Singh, D., "Micro-hydro-power, Resource Assessment Handbook", Asian and Pacific Center for Transfer of Technology of the United Nations, Delhi, Sep 2019.

[17] Pasalli, Y. R., and Rehiara, A. B., "Design Planning of Micro-hydro Power Plant in Hink River", Procedia Environmental Sciences, Vol: 20, pp. 55-63, 2014.

[18] Williamson S. J., Stark B. H. and Booker, J. D., "Low Head Pico Hydro Turbine Selection using a Multi-Criteria Analysis", Renewable Energy, Vol: 61, pp. 43-50, 2014.
[19]Brookshier, P., "Encyclopedia of Energy, Hydropower Technology", Elsevier BV, pp. 333341, New York, 2004.

[20]Elbatran, A. H., Yaakob, O. B., Ahmed, Y. M., and Shabara, H. M., "Operation, Performance and Economic Analysis of Low Head MicroHydropower Turbines for Rural and Remote Areas", Renewable and Sustainable Energy Reviews, Vol: 43, pp. 40-50, 2015.

[21] Fraenkel P, Paish O, Bokalders V, Harvey A, Brown A and Edwards R, "Micro-Hydropower: A Guide for Development Workers", ITDG Publications, London, 1991.

[22] Ramos H and Borga A., "Pumps as Turbines: An Unconventioal Solution to Energy Production", Urban Water, Vol 1, Issue: 3, pp. 261-263, 1999.

[23] Raza, A., Mian, M.S., Saleem, Y., "Modeling of Archimedes Turbine for Low Head Hydro Power Plant in Simulink MATLAB", International Journal of Engineering Research \&technology (IJERT), Vol 2, No. 7, pp. 2471-2477, 2013.

[24] Power, C., McNabola, A., and Coughlan, P., “A Parametric Experimental Investigation of the Operating Conditions of Gravitational Vortex Hydropower (GVHP)", Journal of Clean Energy Technologies, Vol 4, No. 2, pp. 112-119, 2016. 